\title{
A Sensitive Simultaneous Determination of Epinephrine and Tyrosine using an Iron(III) Doped Zeolite-Modified Carbon Paste Electrode
}

\author{
Ali Babaei,* Somaieh Mirzakhani and Balal Khalilzadeh \\ Department of Chemistry, Arak University, Arak, P.O. Box 38156-879, Iran
}

\begin{abstract}
Um eletrodo de pasta de carbono modificado com zeólitas e dopado com ferro(III) foi usado como um sensor eletroquímico de alta sensibilidade e seletividade para a determinação simultânea de pequenas quantidades de compostos biologicamente importantes como epinefrina (Ep) e tirosina (Tyr). Os resultados da voltametria de pulso diferencial (DPV) usando este eletrodo modificado mostra duas ondas anódicas bem traçadas para a oxidação da Ep e da Tyr, as quais tornam possíveis a determinação simultanêa destes compostos. A faixa linear de 0,9 a $216 \mu \mathrm{mol} \mathrm{L}{ }^{-1}$ para a Ep em uma concentração fixa de $30 \mu \mathrm{mol} \mathrm{L^{-1 }}$ Tyr em solução tampão fosfato, $\mathrm{pH}$ 3,0 foi obtida das medidas de DPV usando este eletrodo, com um coeficiente de correlação de 0,9998 e limite de quantificação igual a $0,44 \mu \mathrm{mol} \mathrm{L}{ }^{-1}$. A linearidade obtida para a Tyr na presença de $30 \mu \mathrm{mol} \mathrm{L}^{-1}$ de Ep, foi de 1,2 a $90 \mu \mathrm{mol} \mathrm{L} \mathrm{L}^{-1}$ com um coeficiente de correlação de 0,9989 e limite de quantificação de $0,32 \mu \mathrm{mol} \mathrm{L} \mathrm{L}^{-1}$. O eletrodo modificado apresentou uma boa reprodutibilidade $(\mathrm{RSD}<2.5 \%$ ), baixo limite de quantificação (sub-micromolar) e alta sensibilidade para a detecção de ambos Ep e Tyr com uma elevada estabilidade em sua resposta voltamétrica. O desempenho analítico deste sensor tem sido avaliado para a detecção de epinefrina e tirosina em soro humano e em amostras farmacêuticas com resultados satisfatórios.
\end{abstract}

A Zeolite modified carbon paste electrode doped with iron(III) was used as a highly sensitive and selective electrochemical sensor for simultaneous determination of minor amounts of epinephrine (Ep) and tyrosine (Tyr) as the biologically important compounds. The results of differential pulse voltammetry (DPV) using this modified electrode show two well-resolved anodic waves for the oxidation of Ep and Tyr , which makes it possible for simultaneous determination of both compounds. A linear range from 0.9 to $216 \mu \mathrm{mol} \mathrm{L} \mathrm{L}^{-1}$ for Ep at a constant concentration of $30 \mu \mathrm{mol} \mathrm{L} \mathrm{L}^{-1} \mathrm{Tyr}$ in buffered solution (phosphate buffer, $\mathrm{pH}$ 3.0) was obtained from DPV measurement using this electrode with a correlation coefficient of 0.9998 and a detection limit of $0.44 \mu \mathrm{mol} \mathrm{L}{ }^{-1}$. The linear range, which is obtained for Tyr in the presence of $30 \mu \mathrm{mol} \mathrm{L}^{-1} \mathrm{Ep}$, was in the range from 1.2 to $90 \mu \mathrm{mol} \mathrm{\textrm {L } ^ { - 1 }}$ with a correlation coefficient of 0.9989 and a detection limit of $0.32 \mu \mathrm{mol} \mathrm{L}^{-1}$. The modified electrode had good reproducibility (RSD $<2.5 \%$ ), low detection limit (sub-micromolar) and high sensitivity for the detection of both Ep and Tyr with a very high stability in its voltammetric response. The analytical performance of this sensor has been evaluated for detection of Ep and Tyr in human serum and in a pharmaceutical sample with satisfactory results.

Keywords: Epinephrine, tyrosine, Fe(III) doped zeolite, modified carbon paste electrode

\section{Introduction}

Epinephrine (Ep), Scheme 1 (a), often called adrenaline, is one of the most important neurotransmitters in mammalian central nervous systems, existing in the nervous tissue and body fluid, and controlling the nervous system in the performance of a series of biological reactions and nervous system chemical processes. Many biological reactions, and the nervous system chemical processes

*e-mail: a-babaei@araku.ac.ir can be considered as a type of organic electrochemical process. ${ }^{1,2}$ Therefore, a study on the electrochemical behavior of Ep is a great help in understanding the effects of the nervous system and artificial substitutes, and is of great significance to pharmacological research and the life sciences. Determination of concentrations of Ep is important for the study of neurotransmission, for diagnosis of neurological disorders, such as Parkinson's, and for developing medicines to treat the diseases. ${ }^{3}$ Tyrosine (Tyr), Scheme 1 (b), is a vital constituent of proteins, which are indispensable in human nutrition for establishing 
and maintaining a positive nitrogen balance, ${ }^{4}$ and is the precursor of dopa, dopamine, thyroxin, and epinephrine hormone or neurotransmitters. ${ }^{5,6}$ The absence of Tyr could cause albinism and alkaptonuria, while a high L-tyrosine concentration in culture medium results in increased sister chromatid exchange. Thus, the analytical determination of Tyr is a pharmacological necessity.

Various approaches for Ep analysis include methods such as fluorescence, ${ }^{7-10}$ chemiluminescence, ${ }^{11}$ radioimmunoassay, ${ }^{12}$ capillary electrophoresis ${ }^{13-15}$ and liquid chromatography coupled with several types of detection methods. ${ }^{16,17}$ The detection of tyrosine is usually accomplished by spectrophotometric, ${ }^{18}$ fluorimetric, ${ }^{19}$ and liquid chromatography-tandem mass spectrometry, ${ }^{20}$ gas chromatography-mass spectrometry, ${ }^{21}$ and highperformance liquid chromatography. ${ }^{22}$ These methods are very significant due to their importance in separation science and provide very low detection limits. However, the majority of these methods have some disadvantages, include sample pre-treatment, time consuming and high analysis cost. These disadvantages prevent them for routine analysis. Therefore development of a sensitive and rapid method with low cost for determination of Ep and Tyr is necessary. The development and application of novel electrochemical sensors for $\mathrm{Ep}^{23-26}$ and $\mathrm{Tyr}^{27-30}$ analysis, with respect to their sensitivity, accuracy, and simplicity, has been of greater interest in recent years.

Tyr is a precursor in the production of Ep in biological samples. It has been found that a decrease in the amount of Tyr leads to a decrease in production of Ep in some animals ${ }^{31}$ Tyr and Ep compounds presenting in blood serum. It seems that the application of a sensor for simultaneous determination of Ep and Tyr would be useful to control concentrations of those compounds in some patients. There have been no reports on the application of an electrochemical sensor for simultaneous determination of Ep and Tyr in the literature.

The continuous interest in modified carbon paste electrodes has increased the use of inorganic materials as electrode modifier agents. Among the inorganic materials, zeolites have been widely used as ion exchangers because of their unique size, shape and charge selectivity, high ion exchange capability, high thermal stability, low cost and resistance to extreme conditions. ${ }^{32}$ Substantial efforts have been dedicated to the development of sensors using zeolite-modified electrodes. ${ }^{33-37}$ In this work, we present the application of the iron(III) doped zeolite modified carbon paste electrode $\left(\mathrm{Fe}^{3+} / \mathrm{ZMCPE}\right)$, prepared by mixing iron(III) doped zeolite as the modifier with carbon paste electrode (CPE), for simultaneous determination of Ep and Tyr.
To the best of our knowledge this is the first report on the application of $\mathrm{Fe}^{3+} / \mathrm{ZMCPE}$ for the determination of these compounds. Finally the analytical performance of this sensor for determination of Ep and Tyr in epinephrine injection as a pharmaceutical sample and human serum sample, respectively, was evaluated using the differential pulse voltammetry (DPV) method.

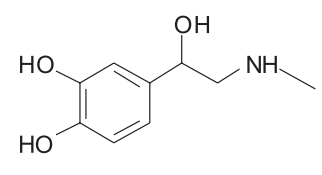

(a)

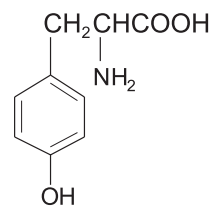

(b)
Scheme 1. Chemical structure of (a) epinephrine and (b) tyrosine.

\section{Experimental}

\section{Reagents and solutions}

All chemicals were analytical grade from Sigma Chemical Company and used without further purification. All solutions were prepared from triply distilled water. Phosphate solution $\left(0.15 \mathrm{~mol} \mathrm{~L}^{-1}\right)$ was prepared by dissolving $10.1 \mathrm{~mL}$ of concentrated orthophosphoric acid in water and diluting it to $1.0 \mathrm{~L}$ in a volumetric flask. The buffer solutions were prepared by addition of $7.5 \mathrm{~mol} \mathrm{~L}^{-1}$ sodium hydroxide to the phosphoric acid solution to reach appropriate $\mathrm{pH}$ values, then the solution volume was adjusted to $1.0 \mathrm{~L}$. Stock solutions of $1 \mathrm{mmol} \mathrm{L}^{-1} \mathrm{Ep}$ and Tyr were freshly prepared in distilled water. Voltammetric experiments on Ep and Tyr were carried out in $0.15 \mathrm{~mol} \mathrm{~L}^{-1}$ phosphate buffer at $\mathrm{pH}$ 3.0. Zeolite $\mathrm{NaY}$ was synthesized in our laboratory as previously reported. ${ }^{38}$

\section{Apparatus}

All the voltammetric measurements were carried out using modified carbon-paste $\left(\mathrm{Fe}^{3+} \mathrm{Y} / \mathrm{ZMCPE}\right)$ as a working electrode, $\mathrm{Ag}|\mathrm{AgCl}| 3 \mathrm{~mol} \mathrm{~L}^{-1} \mathrm{KCl}$ as the reference electrode and platinum wire as the auxiliary electrode. Differential pulse voltammetry experiments were carried out with pulse amplitude of $50 \mathrm{mV}$, scan rate of $20 \mathrm{mV} \mathrm{s}^{-1}$ and a pulse interval of $0.3 \mathrm{~s}$, using an Autolab PGSTAT 30 Potentiostat Galvanostat (EcoChemie, The Netherlands) coupled with a 663 VA stand (Metrohm Switzerland). Cyclic voltammetric measurements were carried out using Autolab PGSTAT 30 Potentiostat Galvanostat by means of three electrode configuration as described for DPV experiments without applying accumulation time at various scan rates. All 
potentials given are with respect to the potential of the reference electrode. $\mathrm{pH}$ measurements were performed with a Metrohm 744 pHmeter using a combination glass electrode.

\section{Electrode preparation}

The iron(III) doped zeolite was prepared as previously reported. ${ }^{37}$ Briefly, $1 \mathrm{~g}$ of $\mathrm{NaY}$ zeolite was lightly ground and immersed in $250 \mathrm{~mL}$ of $0.01 \mathrm{~mol} \mathrm{~L}^{-1} \mathrm{FeCl}_{3}$ solution and stirred for $48 \mathrm{~h}$. The $\mathrm{Fe}^{3+}$ exchanged zeolite was carefully washed with $\mathrm{HCl}$ solution $(\mathrm{pH} 2.0)$ to remove occluded material and surface-adherent salt, washed with triply distilled water to remove chloride ion, and finally dried in room temperature. We have recently reported characterization of the structure of the iron(III) doped zeolite structure. $^{39}$

The zeolite-modified electrode was prepared by mixing $60 \%$ of graphite, $10 \%$ of zeolite powders and $30 \%$ of mineral oil $(\mathrm{m} / \mathrm{m})$. Then the resulting composite was dispersed in diethyl ether solvent to obtain better homogeneity. The mixture was stirred by a magnetic stirrer till the solvent evaporated completely. The prepared composite material was then dried at room temperature for $24 \mathrm{~h}$. The obtained paste was packed into the end of an insulin syringe (i.d. $2 \mathrm{~mm}$ ) and arranged with copper wire serving as external electric contact. The unmodified carbon paste electrode (CPE) was also prepared in the same way as the $\mathrm{Fe}^{3+} \mathrm{Y} / \mathrm{ZMCPE}$ preparation procedure, except that no iron(III) doped zeolite was added. The electrode surface was smoothed on a piece of weighing paper. A new surface could be obtained by pushing an excess of paste out of the tube, removing the excess, and mechanically polishing again the electrode surface.

\section{Results and Discussion}

\section{Electrochemical oxidation of epinephrine and tyrosine}

The cyclic voltammograms were recorded for Ep and Tyr at $\mathrm{Fe}^{3+} / \mathrm{ZMCPE}$ as shown in Figure 1. As can be seen at the surface of the electrode, oxidations of Ep and Tyr are irreversible at the surface of the electrode. These results indicate the slow electron transfer rate for oxidation of these biomolecules at the modified electrode. Such sluggish electron transfer kinetics is related to the electrode fouling caused by the deposition of Ep and Tyr and their oxidation products. Ep shows a reduction peak at $-0.2 \mathrm{~V}$ indicating irreversible reduction of Ep according to Scheme 2a. The effect of potential scan rate on the oxidation response of Ep and Tyr were investigated in the $5-200 \mathrm{mV} \mathrm{s}^{-1}$ scan rate range of scan rate (not shown). A linear relationship between the anodic peak current and the square root of scan rate were found for respectively Ep and Tyr as follows:

$$
\begin{array}{lr}
\operatorname{Ipa}(\mu \mathrm{A})=77.1 v^{1 / 2}\left(\mathrm{~V} \mathrm{~s}^{-1}\right)+0.838\left(\mathrm{R}^{2}=0.992\right) & \mathrm{Ep} \\
\operatorname{Ipa}(\mu \mathrm{A})=10.201 v^{1 / 2}\left(\mathrm{~V} \mathrm{~s}^{-1}\right)+0.5173\left(\mathrm{R}^{2}=0.9942\right) & \mathrm{Tyr}
\end{array}
$$

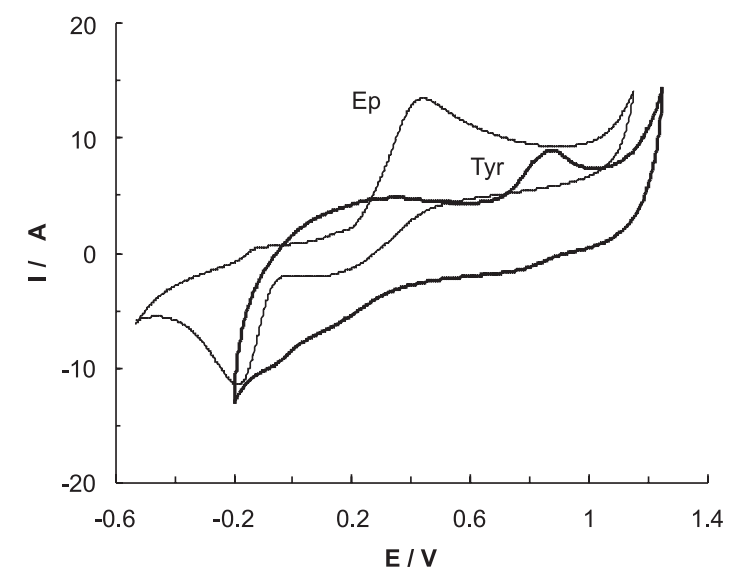

Figure 1. Cyclic voltammograms of $0.1 \mathrm{mmol} \mathrm{L}^{-1} \mathrm{Ep}$ and $0.1 \mathrm{mmol} \mathrm{L}^{-1}$ Tyr at surface of $\mathrm{Fe}^{3+} / \mathrm{ZMCPE}$ electrode in phosphate buffer (pH 3.0) at scan rate of $100 \mathrm{mV} \mathrm{s}^{-1}$.

However, a plot of Ipa for Ep and Tyr vs. v were not linear. The linear relationship between peak currents and square root of scan rates is indicative that the oxidation currents were diffusion controlled, which is the ideal case for quantitative measurements. These phenomena could be due to the rates of adsorption of Ep and Tyr on the electrode surface being slower than the diffusion rates in such a scan rate range.

The differential pulse voltammograms recorded for Ep and Tyr at bare carbon paste (CPE), zeolite modified carbon paste (ZMCPE) and Fe(III) doped modified carbon paste $\left(\mathrm{Fe}^{3+} / \mathrm{ZMCPE}\right)$ electrodes, are shown in Figure 2. Curve a shows the voltammograms of $80 \mu \mathrm{mol} \mathrm{L} \mathrm{L}^{-1} \mathrm{Ep}$ and $80 \mu \mathrm{mol} \mathrm{L}^{-1}$ of Tyr in phosphate buffer ( $\mathrm{pH} 3.0$ ) at CPE. Curves b and c display voltammograms of Ep and Tyr under the same conditions as for curve a at the ZMCPE and the $\mathrm{Fe}^{3+} \mathrm{Y} / \mathrm{ZMCPE}$, respectively. It can be seen for the CPE that very small oxidation peaks were observed for Ep and Tyr. The ZMCPE showed a slight enhancement of the Ep oxidation peak current when compared with CPE. However, no enhancement of the Tyr oxidation peak current was observed. Ep can adsorb a proton at $\mathrm{pH} 3.0$ to form the corresponding cation and therefore could be adsorbed by the zeolite due to the cation exchange character of the zeolite $\mathrm{NaY}$ structure. The differential pulse voltammograms of Ep and Tyr showed excellent improvement in oxidation peak currents for those compounds (curve (c)).There are some reports on the tendency of complex formation between iron(III) and 
Ep ${ }^{40}$ and iron(III) and Tyr. ${ }^{41}$ Therefore Ep and Tyr could become more accumulated on the electrode surface due to their interaction with iron(III). Consequently, application of the $\mathrm{Fe}^{3+} \mathrm{Y} / \mathrm{ZMCPE}$ leads to enhancement of current sensitivity and selectivity in simultaneous determinations of Ep and Tyr compounds.

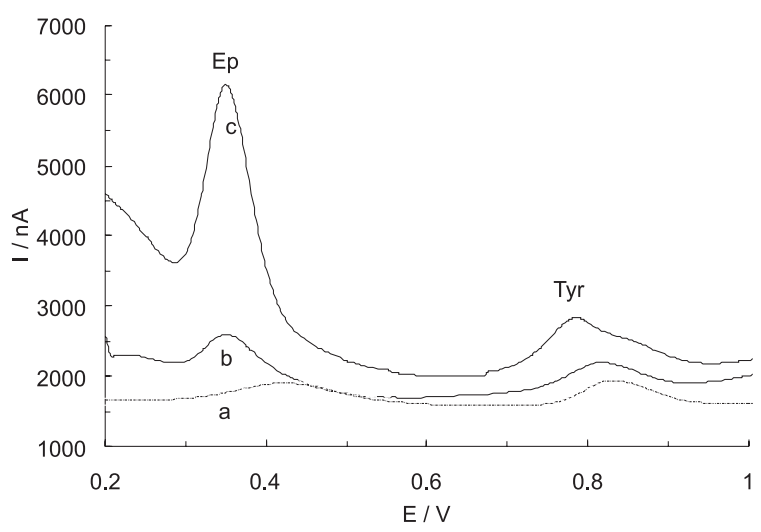

Figure 2. Differential pulse voltammograms of $80 \mu \mathrm{mol} \mathrm{L}-1$ of Ep and $80 \mu \mathrm{mol} \mathrm{L}^{-1} \mathrm{Tyr}$ at (a) bare carbon paste ; (b) zeolite modified carbon paste and (c) $\mathrm{Fe}$ (III) doped modified carbon paste electrodes in phosphate buffer ( $\mathrm{pH}$ 3.0). Other conditions: $\mathrm{E}_{\text {acc }}=-0.2 \mathrm{~V} ; \mathrm{t}_{\text {acc }}=40 \mathrm{~s}$; electrode modification $=15 \%(\mathrm{~m} / \mathrm{m})$; pulse amplitude $=50 \mathrm{mV}$ and scan rate $=20 \mathrm{mV} \mathrm{s}^{-1}$.

\section{Effects of $p H$}

The effects of $\mathrm{pH}$ on the electrochemical response of the $\mathrm{Fe}^{3+} \mathrm{Y} / \mathrm{ZMCPE}$ towards the simultaneous determination of Ep and Tyr solutions were investigated. Variations of peak current with respect to $\mathrm{pH}$ of the electrolyte in the $\mathrm{pH}$ range from 2.0 to 7.0 are shown in Figure 3. It can be seen that the anodic peak current of Ep increases slightly with decrease in the solution $\mathrm{pH}$ from 7.0 to 3.0. In such acidic media Ep (pKa 8.6) would be protonated and then protonated Ep could become accumulated on the $\mathrm{Fe}^{3+} \mathrm{Y} / \mathrm{ZMCPE}$ surface due to the cation exchange properties of the zeolite or the effect of the electrode negative charge at the accumulation potential of $-0.2 \mathrm{~V}$. Further decrease of $\mathrm{pH}$ leads to the corresponding Ep oxidation peak current diminishing. In highly acidic solution the competition between the proton and the protonated form of Ep to adsorb on the $\mathrm{Fe}^{3+} \mathrm{Y} / \mathrm{ZMCPE}$ could have occurred. The oxidation peak current of Tyr was almost independent of variation in $\mathrm{pH}$. Therefore, the optimum solution $\mathrm{pH}$ selected was 3.0. In addition, all the anodic peak currents for the oxidation of Ep and Tyr shifted towards more negative potential with an increase in $\mathrm{pH}$, showing that protons have taken part in their electrode reaction processes. The relationship between $\mathrm{pH}$ and the corresponding peak potentials for Ep and Tyr are shown below:

$$
\begin{aligned}
& \mathrm{E}_{\mathrm{P}}(\mathrm{Ep})=-0.0606 \mathrm{pH}+0.549 \\
& \mathrm{E}_{\mathrm{P}}(\mathrm{Tyr})=-0.054 \mathrm{pH}+0.9823
\end{aligned}
$$$$
\mathrm{R}^{2}=0.9939
$$$$
\mathrm{R}^{2}=0.9967
$$

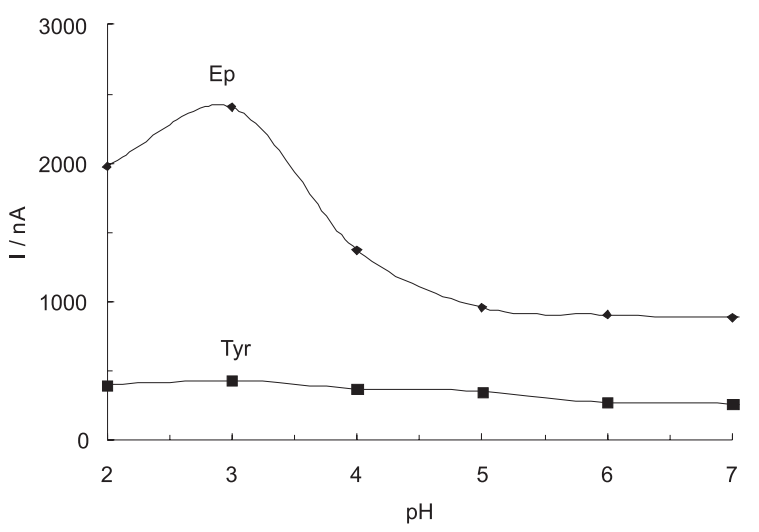

Figure 3. Effect of $\mathrm{pH}$ on the peak currents of oxidation of Ep and Tyr compounds at $\mathrm{Fe}$ (III) doped modified carbon paste electrode in phosphate buffer. Concentrations: Ep: $70 \mu \mathrm{mol} \mathrm{L}^{-1}$ and Tyr: $45 \mu \mathrm{mol} \mathrm{L}^{-1}$. Other conditions are shown as Figure 2.

The slope of $\mathrm{E}_{\mathrm{p}} v s . \mathrm{pH}$ are 60 and $54 \mathrm{mV} / \mathrm{pH}$ which are very close to the anticipated Nernstian value for the process in which the number of protons are equal to the number of transferred electrons. This conclusion is in accordance with the known electrochemical reactions of Ep and Tyr. ${ }^{42,43}$ It has been known that Ep can be oxidized via a two electron and two proton process ${ }^{42}$ and Tyr can be oxidized via a one electron and one proton process. ${ }^{43}$

\section{Effects of accumulation potential}

The effects of accumulation potential on the anodic peak currents of Ep and Tyr solutions were examined over the range -0.5 to $0.3 \mathrm{~V}$. The results showed that the peak current of Ep was slightly increased at an accumulation potential of $-0.2 \mathrm{~V}$. The oxidation peak current of Tyr was almost independent of applied accumulation potential. Thus the accumulation potential of $-0.2 \mathrm{~V}$ was selected as the optimum accumulation potential for further experiments.

\section{Effects of accumulation time}

The effects of accumulation time on differential pulse anodic peak currents for Ep and Tyr were investigated. Initially the peak currents for these compounds increase with accumulation time up to $40 \mathrm{~s}$, however after $40 \mathrm{~s}$ of accumulation time, the peak currents reach a plateau. As a consequence, the accumulation time of $40 \mathrm{~s}$ was chosen as an optimum time for further experiments.

\section{Effect of modifier percent}

The effect of $\mathrm{Fe}^{3+}$ doped zeolite as a modifier in the composition of $\mathrm{Fe}^{3+} \mathrm{Y} / \mathrm{ZMCPE}$ is shown in Figure 4. The 
results showed that the anodic peak current of Ep and Tyr reached the highest value at $15 \%(\mathrm{~m} / \mathrm{m})$ of the modifier at constant value of $30 \%(\mathrm{~m} / \mathrm{m})$ of mineral oil. Higher concentration of modifier showed a decrease in peak current. This is presumably due to reduction of conductivity of the electrode due to decrease in graphite powder concentration. Consequently a carbon paste composition of $15 \%$ modifier zeolite, $55 \%$ graphite and $30 \%$ mineral oil was used in further studies.

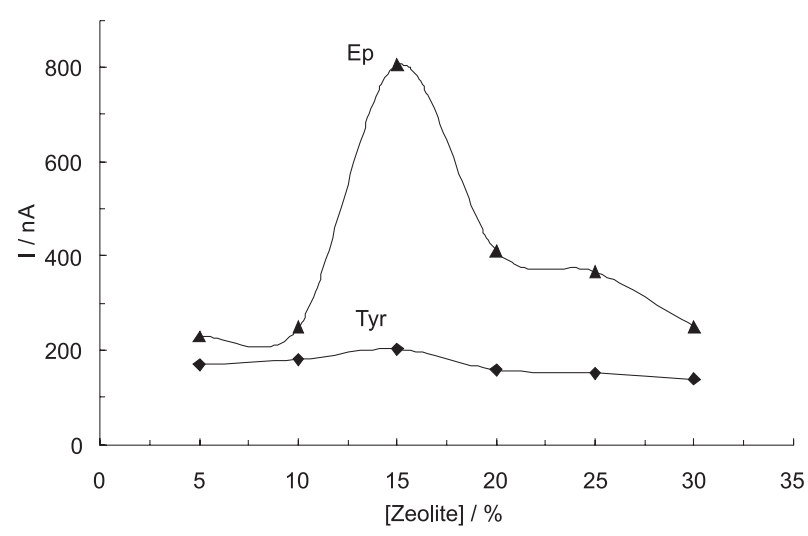

Figure 4. Effect of modifier percent on the peak current of $30 \mu \mathrm{mol} \mathrm{L}-1$ Ep and $30 \mu \mathrm{mol} \mathrm{L}{ }^{-1} \mathrm{Tyr}$ at accumulation time of $40 \mathrm{~s}$. Other conditions are shown as Figure 2.

Linear range, detection limit and reproducibility of the method

To verify the linear relationship between anodic peak currents and Ep and Tyr concentrations several calibration curves were constructed under optimum conditions as accumulation potential of $-0.2 \mathrm{~V}$, an accumulation time of $30 \mathrm{~s}$ and $15 \%(\mathrm{~m} / \mathrm{m})$ iron(III) doped zeolite as a modifier in the $\mathrm{Fe}^{3+} \mathrm{Y} / \mathrm{ZMCPE}$, in $0.15 \mathrm{~mol} \mathrm{~L}^{-1}$ phosphate buffer ( $\mathrm{pH} 3.0$ ) solutions. Figures 5 and 6 show differential pulse voltammograms obtained at $\mathrm{Fe}^{3+} \mathrm{Y} / \mathrm{ZMCPE}$ in various concentrations of Ep and Tyr, respectively. Figure 5 shows DPV at various concentrations of Ep in the presence of $30 \mu \mathrm{mol} \mathrm{L}^{-1}$ Tyr. A linear dynamic range from $0.9 \mu \mathrm{mol} \mathrm{L^{-1 }}$

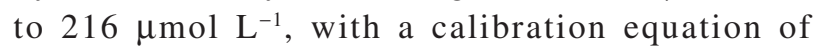
$\mathrm{I}_{\mathrm{p}}(\mathrm{nA})=34.343 \mathrm{c}(\mu \mathrm{mol} \mathrm{L}-1)+2.3197\left(\mathrm{R}^{2}=0.9998\right)$, and a detection limit of $0.44 \mu \mathrm{mol} \mathrm{L}{ }^{-1}$ was obtained. A linear relationship was found for Tyr in the 1.2 to $90 \mu \mathrm{mol} \mathrm{L}^{-1}$

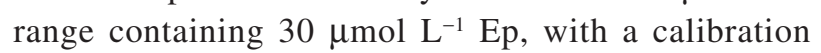
equation of $\mathrm{I}_{\mathrm{p}}(\mathrm{nA})=9.3454 \mathrm{c}\left(\mu \mathrm{mol} \mathrm{L} \mathrm{L}^{-1}\right)+10.635\left(\mathrm{R}^{2}=\right.$ 0.9988 ) and a detection limit of $0.32 \mu \mathrm{mol} \mathrm{L}^{-1}$ (Figure 6).

The linear dynamic range and detection limit of this method were compared with some recent voltammetric methods for determination of Ep or Tyr (Table 1). The results show that the proposed method is preferable in

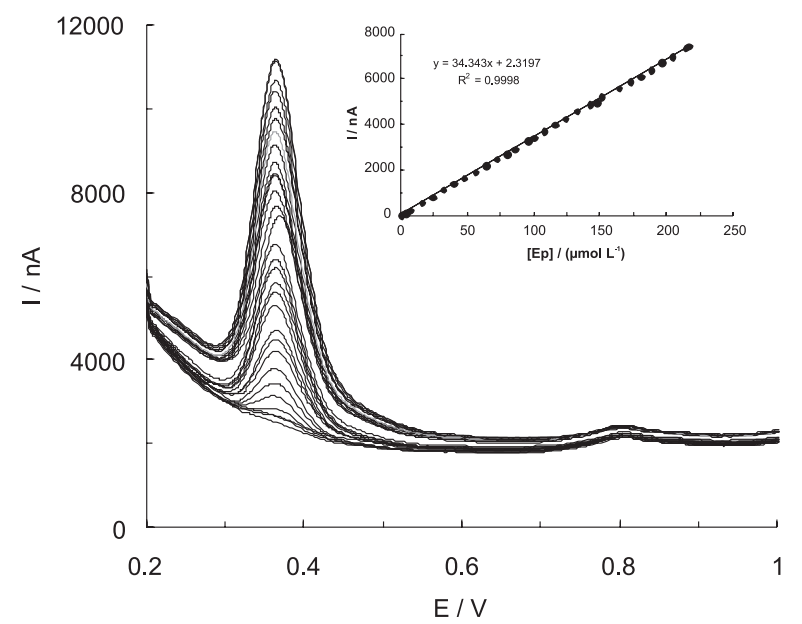

Figure 5. Differential pulse voltammograms for (a) 0.9, (b) 2.0, (c) 4.0, (d) 8.0, (e) 16.0, (f) 32.0, (g) 48.0, (h) 64.0, (i) 80.0, (j) 100.0, (k) 124.0, (l) 142.0, (m) 164.0 , (n) 188.0 and (o) $216.0 \mu \mathrm{mol} \mathrm{L}^{-1}$ of Ep in the presence of $30.0 \mu \mathrm{mol} \mathrm{L}-1$ Tyr at optimum conditions.

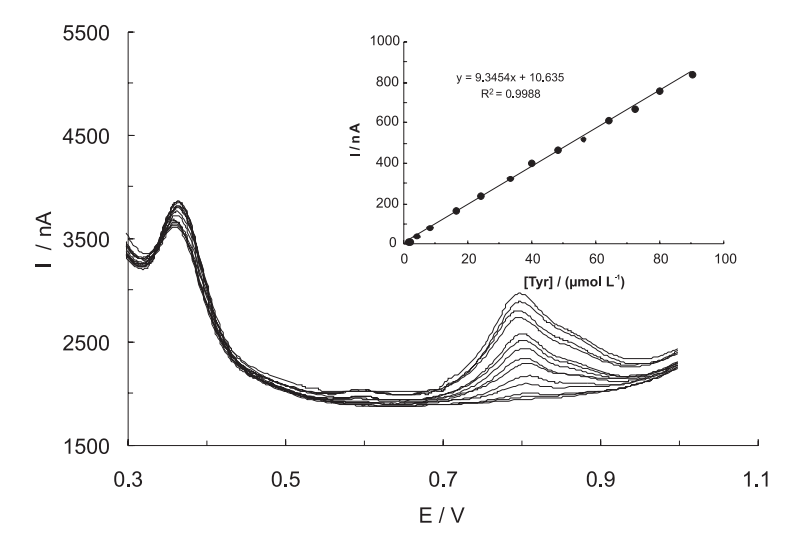

Figure 6. Differential pulse voltammograms for (a) 1.2, (b) 2.0, (c) 4.0, (d) 8.0, (e) 16.0, (f) 24.0, (g) 32.0, (h) 40.0, (i) 48.0, (j) 56.0, (k) 64.0, (l) $72.0,(\mathrm{~m}) 80.0$, and (n) $90.0 \mu \mathrm{mol} \mathrm{L}-1$ of Tyr in the presence of $30.0 \mu \mathrm{mol} \mathrm{L}-1$ Ep at optimum conditions.

determinations of both Ep and Tyr.

\section{Interference studies}

The influences of common interfering species were investigated in the presence of a mixture of $30 \mu \mathrm{mol} \mathrm{L}^{-1}$ Ep and $30 \mu \mathrm{mol} \mathrm{L} \mathrm{L}^{-1} \mathrm{Tyr}$ (Table 2). The results showed that concentrations of the interfering species did not significantly influence the height of the peak currents. The tolerance limit was defined as the concentrations which give an error of $\leq 10 \%$ in the determination of Ep and Tyr compounds.

\section{Analytical applications}

Applicability of the $\mathrm{Fe}^{3+} / \mathrm{ZMCPE}$ was examined for the determination of Tyr in human serum and Ep in epinephrine 
Table 1. Comparison of merits of some voltammetry methods for determination of Ep and Tyr

\begin{tabular}{|c|c|c|c|c|}
\hline Analyte & Modified electrode & Detection limit $\left(\mathrm{mol} \mathrm{L}^{-1}\right)$ & Dynamic range $\left(\mathrm{mol} \mathrm{L}^{-1}\right)$ & Reference \\
\hline \multirow[t]{5}{*}{ Ep } & Poly(eriochrome black T) film modified GCE & $3 \times 10^{-7}$ & $2.5 \times 10^{-6}-5.1 \times 10^{-5}$ & 23 \\
\hline & Electrochemically activated GCE & $8.9 \times 10^{-8}$ & $1 \times 10^{-6}-5.5 \times 10^{-5}$ & 24 \\
\hline & Overoxidized dopamine film modified Au & $3 \times 10^{-7}$ & $2 \times 10^{-6}-8 \times 10^{-4}$ & 25 \\
\hline & Ag-doped poly(L-glutamie acid) modified GCE & $8 \times 10^{-7}$ & $3 \times 10^{-6}-1 \times 10^{-5}$ & 26 \\
\hline & $\mathrm{Fe}^{3+} \mathrm{Y} / \mathrm{ZMCPE}$ & $4.4 \times 10^{-7}$ & $9 \times 10^{-7}-2.16 \times 10^{-4}$ & This work \\
\hline \multirow[t]{5}{*}{ Tyr } & Butyrylcholine modified GCE & $4 \times 10^{-7}$ & $4 \times 10^{-6}-1 \times 10^{-4}$ & 27 \\
\hline & MWCNTs modified GCE & $4 \times 10^{-7}$ & $2 \times 10^{-6}-5 \times 10^{-4}$ & 28 \\
\hline & Boron-doped diamond electrode & $1 \times 10^{-6}$ & $1 \times 10^{-4}-7 \times 10^{-4}$ & 29 \\
\hline & MWCNTs-Au-HPßCD modified GCE & $3 \times 10^{-4}$ & $3.3 \times 10^{-4}-1.2 \times 10^{-3}$ & 30 \\
\hline & $\mathrm{Fe}^{3+} \mathrm{Y} / \mathrm{ZMCPE}$ & $3.2 \times 10^{-7}$ & $1.2 \times 10^{-6}-9 \times 10^{-5}$ & This work \\
\hline
\end{tabular}

MWCNTs $=$ Multi-wall carbon nanotubes; GCE $=$ Glassy carbon electrode; $\mathrm{HP} \beta C D=$ Hydroxypropyl $-\beta$-cyclodextrin

Table 2. Maximum tolerable concentration of interfering species

\begin{tabular}{lcc}
\hline Interfering species & $\begin{array}{c}\mathrm{Ep} \\
\mathrm{C}_{\text {int }} / \mu \mathrm{mol} \mathrm{L}^{-1}\end{array}$ & $\begin{array}{c}\text { Tyr } \\
\mathrm{C}_{\text {int }} / \mu \mathrm{mol} \mathrm{L}^{-1}\end{array}$ \\
\hline $\mathrm{Na}^{+}$ & 50 & 50 \\
$\mathrm{Mg}^{2+}$ & 250 & 250 \\
$\mathrm{~K}^{+}$ & 250 & 250 \\
$\mathrm{Ca}^{2+}$ & 150 & 150 \\
Tartaric acid & 800 & 650 \\
Dopamine & 30 & 100 \\
Cystein & 50 & 60 \\
Phenylalanine & 700 & 900 \\
D-glucose & 1300 & 1700 \\
Citric acid & 2000 & 1200 \\
Glycine & 150 & 170 \\
Acetic acid & 400 & 400 \\
Histidin & 3500 & 4000 \\
Tryptophan & 35 & 30 \\
\hline
\end{tabular}

$\mathrm{C}_{\mathrm{int}}$ refers to interfering compound concentration.

injections and serum. The human serum was diluted with phosphate buffer solution $\left(0.15 \mathrm{~mol} \mathrm{~L}^{-1}, \mathrm{pH} 3.0\right)$ and a $10.0 \mathrm{~mL}$ portion was transferred to the voltammetric cell, individually. The samples were diluted 20 times and spiked with various concentrations of Tyr and Ep. The concentrations were obtained by applying standard addition method. Using the proposed methods described above the diluted (200 times) epinephrine injection was analyzed by applying standard addition method. In addition, a certain volume of standard solution of Ep was added into the corresponding injection for testing recovery. The results were shown in Table 3. The recoveries were from 93.3 to $103.3 \%$, showing that the proposed methods could be efficiently used for the determination of trace amounts of
Table 3. Determination of Ep and Tyr in real samples with $\mathrm{Fe}^{3+} / \mathrm{ZMCPE}$

\begin{tabular}{lcccc}
\hline Sample & Original & $\begin{array}{c}\text { Added } \\
\left(\mu \mathrm{mol} \mathrm{L}^{-1}\right)\end{array}$ & $\begin{array}{c}\text { Found } \\
\left(\mu \mathrm{mol} \mathrm{L}^{-1}\right)\end{array}$ & $\begin{array}{c}\text { Recovery } \\
(\%)\end{array}$ \\
\hline \multirow{3}{*}{ Serum } & Tyr & 3 & 2.8 & 93.3 \\
& & 10 & 10.2 & 102 \\
& & 3 & 14.6 & 97.3 \\
\hline \multirow{3}{*}{ Serum } & Ep & 7 & 2.9 & 96.7 \\
& & 15 & 6.9 & 98.6 \\
Epinephrine & & 0 & 20.0 & 103.3 \\
injection & Ep & 5 & 25.2 & 100.8 \\
& & 10 & 29.5 & 98.3 \\
\hline
\end{tabular}

these compounds in biological systems and pharmaceutical preparations.

\section{Reproducibility and long-term stability of the electrode}

The main advantage of using the $\mathrm{Fe}^{3+} \mathrm{Y} / \mathrm{ZMCPE}$ is easy and quick surface renewal after each use. Thus, the repeatability of the analytical signal has been studied. Indeed, the relative standard deviation (RSD) of $2.73 \%$ and $1.01 \%$ has been obtained for $80 \mu \mathrm{mol} \mathrm{L}^{-1}$ Ep and $60 \mu \mathrm{mol} \mathrm{L}{ }^{-1} \mathrm{Tyr}$, respectively in ten consecutive determinations. It should be noted that the $\mathrm{Fe}^{3+} \mathrm{Y} /$ ZMCP electrode surface was polished, as described in experimental section, before each consecutive determination. Another attraction of the proposed modified electrode was that the resulting carbon paste electrode showed a good long-term stability. Stability of the proposed electrode was tested by measuring the decrease in voltammetric current during repetitive DPV measurements of Ep and Tyr with $\mathrm{Fe}^{3+} \mathrm{Y} / \mathrm{ZMCPE}$ stored in solution or air. For example, determination of 
$40 \mu \mathrm{mol} \mathrm{L}-1$ Ep, $40 \mu \mathrm{mol} \mathrm{L}^{-1}$ Tyr in $0.15 \mathrm{~mol} \mathrm{~L}^{-1}$ phosphate buffer solution ( $\mathrm{pH} 3.0$ ), when the modified electrode was subjected to an experiment every $30 \mathrm{~min}$, gave no significant change in the voltammetric currents up to $24 \mathrm{~h}$. When the electrode was stored in the atmosphere, the current response remained almost unchanged for 40 days. The high stability of the zeolite-modified carbon paste electrode could be related to the strong affinity of zeolite $\mathrm{Y}$ for iron(III) ${ }^{44}$ and the insolubility of the zeolite in water.

\section{Conclusions}

In the present work, we introduced a new electrode based on iron(III) doped zeolite modified carbon paste. Iron(III) loaded in a zeolite matrix can increase anodic peak currents by adsorption of Ep and Tyr compounds on the electrode surface. The results indicated that the $\mathrm{Fe}^{3+} \mathrm{Y} / \mathrm{ZMCPE}$ facilitates the simultaneous determination of Ep and Tyr with good sensitivity and selectivity. The electrode showed high stability in repetitive experiments due to the high affinity of zeolite $\mathrm{Y}$ for iron(III) and the low solubility of the zeolite in water. The effects of potential interfering ions were studied, and it was found that the proposed procedure was free from interferences of most common interfering ions and organic compounds. The proposed sensor was used with satisfactory results in determinations of Ep and Tyr in some real samples like diluted human serum and epinephrine injection without the necessity of using sample pretreatment or any time-consuming extraction or evaporation steps prior to the analysis. The simple fabrication procedure, good reproducibility, high stability, wide linear dynamic range, low detection limit, high sensitivity and a distinct advantage of polishing in the event of surface fouling, suggest that this electrode is an attractive candidate as a sensor for practical applications.

\section{Acknowledgments}

The authors gratefully acknowledge the financial support of this work by the research council of Arak University. Thanks to Dr. A. James McQuillan from Otago University in New Zealand for his valuable comments.

\section{References}

1. Zhao, Q.; Gan, Z.; Zhuang Q.; Electroanalysis 2002, 14, 1609.

2. Ijima, S.; Nature 1991, 354, 56.
3. Wightman, R. M.; May, L. J.; Michael, A. C.; Anal. Chem. 1988, 60, 769A.

4. Jin, G. P.; Lin, X. Q.; Electrochem. Commun. 2004, 6, 454.

5. Carlsson, A.; Lindqvist, M.; Arch, N.S.; Pharmacology 1978, 303, 157.

6. Femstrom, H.F.; Femstrom, J.D.; Life Sci. 1995, 57, 97.

7. Nohta, H.; Yukizawa, T.; Ohkura, Y.; Yoshimura, M.; Ishida, J.; Yamaguchi, M.; Anal. Chim. Acta 1997, 344, 233.

8. Llavero, M. P.; Rubio, S.; Gomez-Hens, A.; Perez Bendito, D.; Anal. Chim. Acta 1990, 229, 27.

9. Canizares, P.; Luque De Castro, M. D.; Anal. Chim. Acta 1995, 317, 335.

10. Guo, Y.; Yang, J.; Wu, J.; Du, A.; J. Fluores. 2005, 15, 131.

11. Guo, Z.; Dong, S., Electroanalysis 2005, 17, 607.

12. Murphy, J. F.; Davies, D.H.; Smith, C. J.; J. Immunol. Methods. 1992, 154, 89.

13. Wei, S.; Song, G.; Lin, J.-M.; J. Chromatogr., A 2005, 1098, 166.

14. Zhu, R.; Kok, W. T.; Anal. Chem. 1997, 69, 4010.

15. Siren, H.; Karjalainen, U.; J. Chromatogr., A 1999, 853, 527.

16. Zhang, S.; Xu, Q.; Zhang, W.; Jin, L.; Jin J.-Y.; Anal. Chim. Acta 2001, 427, 45.

17. Xu, F.; Gao, M.; Shi, G.; Wang, L. Zhang, W.; Xue, J.; Jin, L.; Jin, J.-Y.; Anal. Chim. Acta 2001, 439, 239.

18. Azuma, Y.; Maekawa, M.; Kuwabara, Y.; Nakajima, T.; Taniguchi, K.; Kanno, T.; Clin. Chem. 1989, 35, 1399.

19. Wang, F.; Wu, K. Z.; Qing, Y.; Ci, Y. X.; Anal. Lett. 1992, $25,1469$.

20. Orhan, H.; Vermeulen, N. P. E.; Tump, C.; Zappey, H.; Meerman, J. H. N.; J. Chromatogr., B 2004, 799, 245.

21. Deng, C. H.;. Deng, Y. H; Wang, B.; Yang, X. H.; J. Chromatogr., B 2002, 780, 407.

22. Sabine, L.; Jean, P. G.; Joelle, S.; Bernard, B.; J. Chromatogr., B 1997, 696, 9.

23. Yao, H.; Sun, Y.; Lin, X.; Tang, Y.; Liu, A.; Li, G.; Li, W.; Zhang, S.; Anal. Sci. 2007, 23, 677.

24. Qiao, J. X.; Luo, H. Q.; Li, N. B.; Colloids Surf., B 2008, $62,31$.

25. Luczak, T.; Electroanalysis 2008, 20, 1317.

26. Hu, W.; Sun, D.; Ma, W.; Chem. Anal. (Warsaw, Pol.) 2008 , 53,703 .

27. Jin, G.-P.; Lin, X.-Q.; Electrochem. Commun. 2004, 6, 454.

28. Xu, Q.; Wang; S.-F.; Microchim. Acta 2005, 151, 47.

29. Zhao, G.; Qi, Y. Electroanalysis 2006, 18, 830.

30. Yogeswaran, U.; Thiagarajan, S.; Chen, S. M.; Carbon 2007, 45, 2783.

31. Lee, P.V.; J. Pharmacol. Exp. Ther. 1954, 112, 291.

32. Walcarius, A.; Electroanalysis 1996, 8, 971.

33. Wang, J.; Walcarius, A.; J. Electroanal. Chem. 1996, 407, 183.

34. Wang, J.; Walcarius, A.; J. Electroanal. Chem. 1996, 404, 237. 
35. Rando, M. D. C.; Rodriguez, I. N.; Cisneros, H. H.; Anal. Chim. Acta 1998, 370, 231.

36. Jiang, Y.; Zou, M.; Yuan, K.; Xu, H.; Electroanalysis 1999, $11,254$.

37. Mazlum Ardakani, M.; Akrami, Z.; Kazemian, H.; Zare, H. R.; J. Electroanal. Chem. 2006, 586, 31.

38. Breck, D. W.; Tonawanda, N. Y.; assigned to Union Carbide Corporation; Patent 3130007, 1964.

39. Babaei, A.; Zendehdel, M.; Khalilzadeh, B.; Taheri, A.; Colloids Surf., B 2008, 66, 226.

40. Sandra, L. J.; Sue, E.; Lovis, G; J. Inorg. Biochem. 1997, $66,165$.
41. Durmus, A.; Eichen, C.; Sift, B. H.; Kratel, A.; Kappl, R.; Huttermann, J. Krebs, B.; Eur. J. Biochem. 1999, 260, 709.

42. Chen, S.-M.; Peng, K.-T .; J. Electroanal. Chem. 2003, 547 179.

43. Jin, G.-P.; Lin, X.-Q .; Electrochem. Commun. 2004, 6, 454.

44. Jiang, Y.; Zou, M.; Yuan, K.; Xu, H.; Electroanalysis 1999, $11,254$.

Received: December 22, 2008 Web Release Date: November 12, 2009 